\title{
A CASHLESS SOCIETY FOR ALL: DETERMINING CONSUMERS' READINESS TO ADOPT MOBILE PAYMENT SERVICES
}

\author{
M. Humbani* and M. Wiese \\ Department of Marketing Management, University of Pretoria, Hatfield, South Africa
}

*CONTACT M. Humbani. Department of Marketing Management, University of Pretoria, Private Bag X20, Hatfield0028, South Africa. Email: M.Humbanimichael.humbani@up.ac.za

\begin{abstract}
The technology readiness index was applied to determine consumers' readiness to adopt mobile payment services and the moderating effect of gender. Gender has been identified as a key variable in adoption and its vital role in market segmentation and gender empowerment obliges its inclusion. The results of the regression analysis indicate that convenience and compatibility drive consumers' adoption whereas risk, cost and insecurity are inhibitors. Furthermore, gender moderates only the relationship between convenience and the adoption of mobile payment services. Given the moderating effect of gender, companies should initiate advertising campaigns targeting women opinion leaders in advertisements, which can in turn encourage and educate other women to enjoy the convenience of mobile payments. Results provide insights on how to increase adoption and reduce the gender gap in mobile payment services.
\end{abstract}

\section{Keywords}

Adoption, technology readiness index (TRI), drivers, inhibitors, mobile payment services, gender. 


\section{Introduction}

The rapid adoption of mobile phones and their role in the development of personal and professional activities has been one of the most important technological events in recent decades (Liebana-Cabanillas, de Luna \& Montoro-Rios, 2015). Global statistics indicate that mobile subscriptions worldwide have passed the 7 billion mark, of which about 770 million are estimated to be in Africa alone (ITU, 2016). The above figure of seven billion indicates the number of SIM cards in a country expressed as a percentage of the country's population.

In the light of this development, merchants, financial institutions and telecommunication operators are focusing their efforts on increasing the number of mobile-enabled services available to mobile phone users. These advances in mobile technology are having a profound impact on people's daily lives; and they are beginning to offer interesting advantageous new services (Kim, Mirusmonov \& Lee, 2010). One area that is experiencing exponential growth is the mobile payment service (Liebana-Cabanillas et al., 2015), which enables users to pay for goods and services by using their mobile phones wherever they go (Kim et al., 2010).

Mobile payment services are now available in $61 \%$ of the world's developing countries and about 53\% of active global mobile payment services are in Sub-Saharan Africa (GSMA, 2014). Forecasts suggest that global mobile payment services will have 450 million users and $\$ 721$ billion in transaction value by 2017 (Slade, Williams \& Dwivedi, 2014). Due to this expected growth, it is suggested that mobile payments will change lives and ways of conducting business; since consumers and mobile devices have become inseparable (Lee, Park, Chung \& Blakeney, 2012).

South Africa has the highest rate of smartphone and mobile penetration in Africa, representing $51 \%$ of smartphones and $133 \%$ mobile penetration, followed by Kenya with $31 \%$ of smartphones and $70 \%$ mobile penetration, and then, Nigeria with $29 \%$ and $72 \%$, 
respectively (Fripp, 2014). Based on these statistics, it can be said that South Africans are prolific users of mobile phones, thus making South Africa a prime market for mobile payment services. Considering this state of affairs, it is surprising to note that by the end of 2014 only 2.1 million South Africans were using QR code-based mobile payment applications to perform transactions of various kinds (World Wide Worx, 2014).

While service providers such as merchants, banks and mobile network operators are actively promoting mobile payment services, the intention to adopt mobile payment services is still low (Chong, Chan \& Ooi, 2012). The key question faced by the service providers is how to transfer the potential mobile payment service into financial profits. Thus, the research question addressed in this study is: What are the salient motivations that drive or inhibit consumers from adopting mobile payment services? The answer to this question is important as service providers cannot recover their investments, or tailor-make and adapt their marketing strategies accordingly unless consumers do adopt and use mobile payment services (Jia, Hall \& Sun, 2014).

Gender has been identified as a key variable in the adoption and use of mobile technology (Chong et al., 2012; Kabata, 2015). Therefore, gender is included in this study as a moderating variable to determine its influence on the adoption of mobile payment services. Successful targeting of mobile payments across genders will not only advance financial inclusion, but also unlock significant growth opportunity for the mobile payment industry (GSMA, 2014). Targeting women through mobile payments can unlock an estimated $\$ 170$ billion market opportunity by 2020 (GSMA, 2014).

Although the local media in South Africa continuously create a buzz to signal the continued use of mobile-payment services, little is known about the factors that drive the adoption of such mobile payment services. The high mobile penetration rates in South Africa of $133 \%$ 
(Fripp, 2014) do not tally with the real transactions and payments. Such a situation calls for more research to identify the factors that influence adoption (Zhou, 2013). There is abundant international research focusing primarily on the factors that influence the adoption of mobile payment services (Chong et al., 2012; Mallat, 2007; Pham \& Ho, 2015), however, evidence is almost non-existent to suggest that similar studies have been conducted in an emerging market such as that of South Africa.

Because of the differences in consumer profiles in different parts of the world, it may be prudent to deal with consumer related issues differently. A study of this nature is important, particularly in South Africa where consumers use their smartphones for an average of 127 minutes per day, with tablets taking up 63 minutes per day on average (Business Tech, 2014). Marketers in developing countries are keen to know the factors that influence the rate of adoption of new technologies because that information determines the marketing effort and the allocation of resources to support the launch of the new technology (Mpinganjira, Dos Santos, Botha, Du Toit, Erasmus, Maree, \& Mugobo, 2013).

This study investigates those factors that influence the adoption of mobile payment services in order to suggest recommendations to increase the adoption levels. Understanding the adoption of mobile phone payment and the moderating effects of gender could greatly benefit service providers, such as the retail industry, the banking industry and telecommunication operators in growing their businesses (Kim et al., 2010).

This study makes two contributions to theory and practice. Firstly, the factors that drive and inhibit the adoption of mobile payment services are investigated using an updated framework of the Technology Readiness Index (Parasuraman, 2000) in order to complement earlier international mobile payment adoption studies, and to validate the determinants of mobile payment adoption in the context of an emerging economy. To realise this theoretical 
contribution, the study builds on the less-applied TRI in mobile payment adoption studies (Lin, Shih \& Sher, 2007) and adding other constructs that have been reported in the literature to have a significant influence on consumers' adoption of mobile payment services.

Secondly, from a practical perspective, understanding the factors that influence the adoption of mobile payment services would assist service providers to achieve a competitive advantage (Kim et al., 2010). Of particular importance to managers of mobile payment services is how effectively to boost the number of users. The results of the study should help service providers more effectively to invest the appropriate time, effort and money in the development, provisions and marketing of mobile payment services (Kim et al., 2010).

\section{Background}

\section{Mobile payments}

The first example of mobile payments came in 1997 when Coca Cola introduced a limited number of vending machines, from which the consumer could make a mobile purchase. The consumer would send a text message to the vending machine to set up payment and the machine would then release the product (Dahlberg, Guo \& Ondrus, 2015). Mobile payment research started soon after the first mobile payment transaction in 1997 (Dahlberg et al., 2015). Since then, mobile payments have been subject to different conceptualisations.

According to Liebana-Cabanillas, Sanchez-Fernandez and Munoz-Leiva (2014), mobile payment can be defined as any type of individual or business activity involving an electronic device with a connection to a mobile network, enabling the successful completion of an economic transaction. Mallat (2007) defines mobile payments as the use of a mobile device to conduct a payment transaction, in which money or funds are transferred from the payer to the receiver via an intermediary, or directly, without an intermediary. Despite these 
conceptualisations, the mobile phone is emphasised as the key characteristic distinguishing mobile payments from other forms of payments (Schierz, Schilke \& Wirtz, 2010).

The above mobile payment definitions refer to some kind of monetary value transfer with three main entities: the mobile service provider (e.g., Standard Bank's SnapScan), the mobile payment vendor (e.g., the merchant), and the mobile technology in use (e.g., 3G network) (Qasim \& Abu-Shanab, 2015). For the purpose of this study, mobile payment is defined as the ability of a mobile phone user to initiate, authorise, and complete a financial transaction, in which money or funds are transferred over the mobile network, or via the wireless communication technologies to the receiver through the use of a mobile device (Slade et al., 2014).

This definition is suitable for this study because it refers mainly to the completion of payments and transactions between three main parties (banks, mobile network service providers and retailers) in a fast, convenient, safe, and simple way, at anytime and anywhere, using a mobile device.

Mobile payments can be categorised into various ways. According to Zhou (2013), mobile payments are categorised into remote payments and proximity payment options. Remote payments require the users to connect with the remote payment servers, in order to conduct payment, such as mobile banking and the mobile internet payment service. Proximity payments, on the other hand, require the users to conduct payment via their mobile phones without connecting to the remote server, such as paying bus fares, meals at restaurants, as well as other services (Zhou, 2013). Proximity payments are also referred to as mobile pointof-sale (mPOS) payments to represent payments that take place when the customer is in close proximity to the merchant (GSMA, 2015). In this type of payment, the credentials of the transaction are stored on the mobile phone and exchanged within a small distance by using 
barcode scanning or radio frequency identification (RFID) technology (Qasim \& AbuShanab, 2015).

The above chosen definition for this study encompasses both proximity and remote mobile payments services for daily purchases, as well as the payment of accounts, applied in the context of an emerging economy.

\section{Development of the theoretical model}

\section{Theoretical background}

Extant literature has drawn on a number of information technology theories to explain the adoption of new technology. These include the technology-acceptance model (TAM) (Davis, 1989), universal technology adoption and use theory (UTAUT) (Venkatesh \& Davis, 2000), the theory of reasoned action (TRA) (Ajzen, 1991), the theory of planned behaviour (TPB) (Ajzen, 1991), the diffusion of an innovation theory (IDT) (Rogers, 1995), as well as the technology readiness index (TRI) (Parasuraman, 2000) models which have prominently been instrumental in explaining the adoption of new technology in a variety of contexts. This study is based on the technology readiness index (TRI).

Technology readiness refers to people's propensity to embrace and use new technologies for accomplishing goals at home, in life, and at work (Parasuraman \& Colby, 2014). The TRI was chosen to ground this study for several reasons. Firstly, the TRI considers individual differences to explain consumers' intention to adopt a new technology (Parasuraman, 2000). The TRI is individual-specific, as opposed to other models, such as the TAM, which is system-specific (Parasuraman, 2000). Since the traits differ among people, so are their beliefs about the various aspects of technology; and the relative strength of each trait indicates a person's openness to technology (Walczuch, Lemmink \& Streukens, 2007). 
Secondly, the TR index differentiates between the drivers and the inhibitors of technology adoption (Parasuraman, 2000), which is in line with the objectives of this study that is aimed to investigate the drivers and the inhibitors of mobile payment services.

Thirdly, the TRI has been updated and streamlined in terms of content, structure and psychometric properties to reflect significant changes in the technology landscape (Parasuraman \& Colby, 2014). The original TRI comprised 36-item scales, which have been streamlined down to 16-item scale items. Finally, the research indicates that the success of a technology innovation implementation depends as much on individual differences as on the technology itself (Lu, Yu, Liu \& Yao, 2003).

The TR construct can be viewed as an overall mind-set resulting from a combination of mental drivers and inhibitors that collectively determine a person's predisposition to use new technologies (Parasuraman, 2000). Thus, it was considered applicable to be employed to measure the adoption of mobile payment services in this study. The TRI comprises four subdimensions: optimism, innovativeness, discomfort, and insecurity (Parasuraman \& Colby, 2014). Optimism and innovativeness are drivers of TR; while discomfort and insecurity are inhibitors thereof (Lin et al., 2007).

To recognise the differences in individual consumer's adoption of mobile payment services, and the widening scope of the elements of new technology adoption studies (Yang, Lu, Gupta, Cao \& Zhang., 2012), this study incorporates other variables from prior studies that have been reported as significant drivers and inhibitors of consumers' readiness to adopt mobile payment services. The additional drivers include: convenience (Obe \& Balogun, 2007; Kim et al., 2010; Teo, Tan, Ooi, Hew \& Yao, 2015), and compatibility (Mallat, 2007; Liebanna-Cabanillas et al., 2015) while additional inhibitors included in the framework are 
the perceived cost (Mallat, 2007; Lu, Yang, Chan \& Cao, 2011; Chong et al., 2012) and the perceived risk (Mallat, 2007; Yang et al., 2012; Pham \& Ho, 2015), as discussed below.

These factors require further investigation not only because a number of studies have reported them as significant predictors, but also to investigate their predictability in the South African context.

\section{Conceptual framework and hypotheses}

Figure 1 shows the conceptual framework of the drivers and the inhibitors of consumers' readiness to embrace mobile payment technologies. To assist managers in developing appropriate gender-segmentation strategies, this study investigates the adoption of mobile payment services by investigating the moderating effects of gender.

Figure 1: Technology-readiness framework

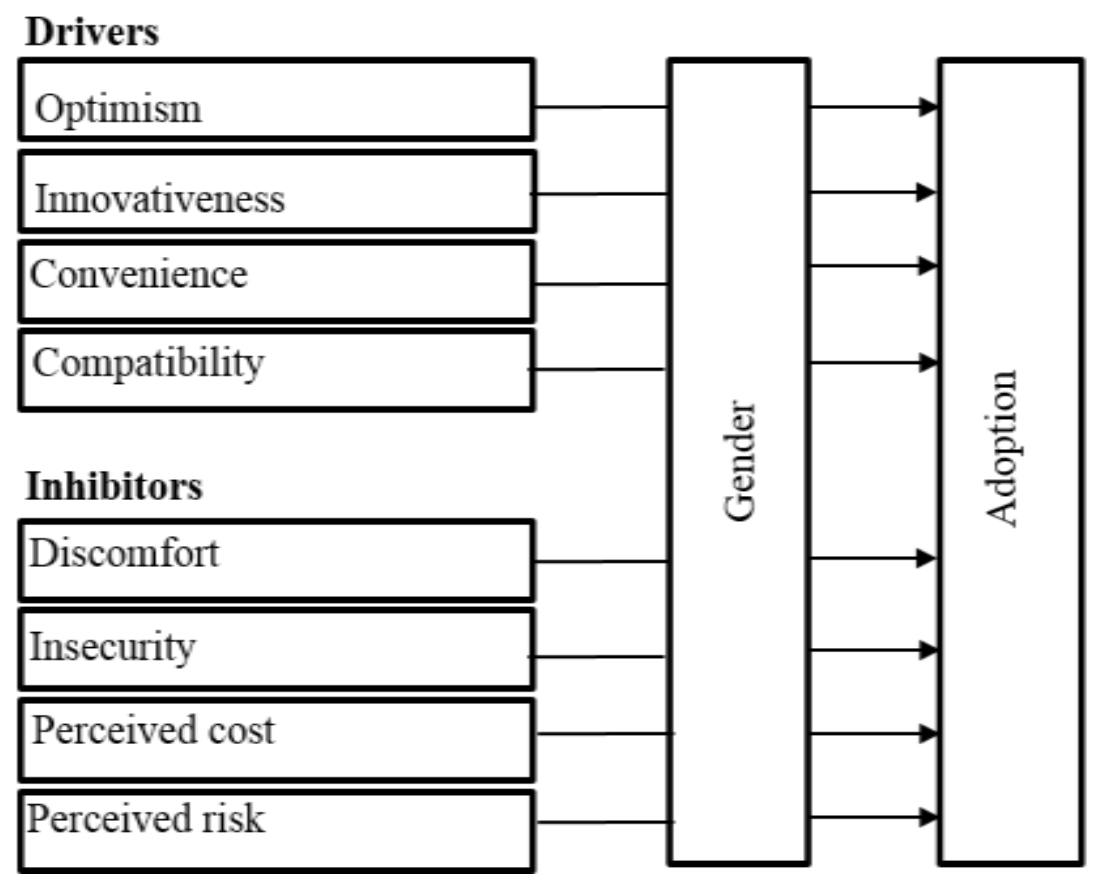

The adoption of mobile payment services has been widely studied (Mallat, 2007; Lin et al., 2007; Liebana-Cabanillas et al., 2014). Rogers (1995) considered the adoption process as a 
learning process that is influenced by a group of dynamics involving four processes: the awareness stage, the evaluation stage, the trial stage, and the adoption stage. According to Straub (2009:629), consumer adoption refers to the individual's decision whether to integrate an innovation into his or her life, while Kiwanuka (2015) defines adoption as the use of a technology for the first time. These definitions given by various authors show that there is no universally accepted definition and usage of the term. However, the above definitions indicate the propensity to accept new information technology and they can serve as the viewpoint from which to examine users' adoption of mobile payment services (Kiwanuka, 2015).

For the purpose of this study, adoption is defined as the mental process an individual passes from first hearing about an innovation (mobile payment app) to the final adoption thereof (downloading the app) (Rogers, 1995). Downloading an app is an important initial step but it is important to dwell on the sparsely researched area of the adoption of mobile payment services after an initial downloading. The following section discusses the factors that influence the adoption of mobile payment services.

\section{Optimism}

Optimism is defined as a positive view of technology and a belief that it offers people increased control, flexibility, and efficiency in their lives (Parasuraman \& Colby, 2014). Optimists use more active coping strategies than pessimists and these strategies are more effective in achieving positive outcomes (Walczuch et al., 2007). These authors further contend that optimists are less likely to focus on the negative events and thus, they confront technology more openly. Previous studies have reported that optimism leads to more positive attitudes and it would help bring out more positive attitudes towards technology (Walczuch et al., 2007; Lin et al., 2007). 
Based on the above, it can be hypothesised that:

$\mathrm{H}_{1}$ : Consumers' optimism regarding mobile payments positively influences the adoption of mobile payment services.

\section{Innovativeness}

The personal innovativeness of individuals influences their acceptance attitude towards mobile services (Lee et al., 2012). Personal innovativeness is explained as the inclination of an individual to try out any new information systems and it has a significant and positive effect on mobile payment services (Kim et al., 2010). Personal innovativeness is considered to be a trait and a relatively stable descriptor of an individual and invariant across situations (uninfluenced by environmental or internal variables (Walczuch et al., 2007). As mobile payment is an innovative technology in the mobile market that is likely to be a worldwide trend in a few years, it is possible that personal innovativeness could affect the intended use of mobile payment services (Liebana-Cabanillas et al., 2015).

This assumption is justified based on previous studies that reported that individuals with high levels of personal innovativeness in information technology develop more positive perceptions about the innovation (Yang et al., 2012). Therefore, it can be hypothesised that:

$\mathrm{H}_{2}$ : Consumer innovativeness regarding mobile payments positively influences the adoption of mobile payment services.

\section{Convenience}

Convenience has been reported in the literature, as one of the important factors predicting the success of mobile payments. According to Kim et al. (2010), consumers believe in the benefits of technology when the technology makes people's lives easier and it ameliorates the difficulty of performing common tasks. Convenience can also be described as an important 
characteristic of the mobile device. These devices store data and they are always at hand, and they are increasingly becoming easy to use (Obe \& Balogun, 2007). This assertion is supported by Teo et al. (2015), who reported that the convenience of having a single payment device to substitute multiple payment alternatives contributes to the benefits of mobile payments. Convenience of mobile payments is also enhanced by the fast internet connectivity to a mobile phone characteristic of many countries (Obe \& Balogun, 2007).

Thus, many studies (Obe \& Balogun, 2007; Liao, Shi \& Wong, 2012; de Kerviler, Demoulin \& Zidda, 2016) have reported significant positive relationships between convenience and the adoption of mobile payment services, hence, the construct was included in this study as a driving variable. In the light of the above, the following hypothesis was formulated:

$\mathrm{H}_{3}$ : Consumer's perceptions of convenience regarding mobile payments positively influences the adoption of mobile payment services

\section{Compatibility}

In the adoption of new technologies, compatibility has been defined as the consistency between an innovation and its values, experiences and the needs of potential adopters (Rogers, 1995). Previous scholars have found compatibility to be an important predictor for the adoption of mobile payment apps (Liebana-Cabanillas et al., 2015; Mallat, 2007), particularly if the technology is new (Ramos-de-Luna, Montoro-Rios \& Liebanna-Cabanillas, 2015), such as is the case with mobile payment apps. According to Mallat (2007), the consumers' ability to integrate mobile payment apps into their daily lives in terms of purchase transactions and habits is an important determinant of consumers' willingness to adopt mobile payment services. 
As suggested by Liebana-Cabanillas (2015), the compatibility variable includes the coherence of an innovation with the values, behaviour patterns and experiences of an individual. Based on the above, it can be hypothesised that:

$\mathrm{H}_{4}$ : Consumers' perceptions of compatibility regarding mobile payments positively influence the adoption of mobile payment services.

\section{Insecurity}

One of the major barriers to the use of mobile payments is the feeling of insecurity. It is necessary to establish new security systems for mobile payment methods to ensure the security of customer transactions and to generate confidence thereby improving attitudes toward them (Ramos-de-Luna et al., 2015). This is so because security threats in mobile devices are more challenging than those in personal computers as mobile devices are easily lost or stolen (Liu, 2015). Insecurity is described by Parasuraman and Colby (2014) as the distrust of technology stemming from scepticism about its ability to work properly and concerns about its potentially harmful consequences. Users fear that hackers may obtain data through Bluetooth or radio frequency identification (RFID) or alternatively, the mobile device may be infected by malware through the downloading and scanning of QR-codes (Liu, 2015). Therefore, insecurity is more likely to negatively affect the adoption of mobilepayment services.

Therefore, the following hypothesis was formulated:

$\mathrm{H}_{5}$ : Consumers' perceptions of insecurity regarding mobile payments negatively influence their adoption of mobile payment services 


\section{Discomfort}

Discomfort is described as a perceived lack of control over technology and a feeling of being overwhelmed by it (Parasuraman \& Colby, 2014). Users who score highly on the discomfort scale suffer from a perceived lack of control and a sense of being overwhelmed by technology (Walczuch et al., 2007). Hence, they will perceive technology as more complex. These findings have been corroborated in prior studies that reported that high levels of discomfort with regard to technology can lead to negative attitudes towards the technology (Walczuch et al., 2007; Parasuraman \& Colby, 2014). Based on the above, the following hypothesis was formulated:

$\mathrm{H}_{6}$ : Consumers' perceptions of discomfort regarding mobile payments negatively influence their adoption of mobile payment services.

\section{Perceived cost}

In a study by Mallat (2007), the pricing of mobile payments had a significant negative impact on consumer adoption willingness. The results of their study indicated that mobile payments that pass on the transaction costs to consumers are not likely to succeed unless they are able to provide superior advantages. In a similar study by Lu et al. (2011), 60\% of their respondents were concerned with the costs of using mobile payment services. Chong et al. (2012) also found that cost has a significant and negative relationship on Malaysian consumer decisions to adopt mobile payment services. Based on the above, it can be hypothesised that:

$\mathrm{H}_{7}$ : Consumers' perceived the cost regarding mobile payments negatively influences their adoption of mobile payment services. 


\section{Perceived risk}

Due to the higher levels of uncertainty that are associated with services, services are considered to be riskier than products (Pham \& Ho, 2015). Prior studies have considered the perception of risk as a deterrent to the adoption of mobile payments (Mallat, 2007; Pham \& Ho, 2015; Yang et al., 2012). Perceived risk refers to the subjective expectation of a loss or sacrifice in using a risky technology (Pham \& Ho, 2015). Mallat (2007) identified several dimensions of risk. Participants in her study identified the risks associated with the possibility that someone would be able to pay with their mobile phone if the device was lost. Other participants identified risk in terms of the possibility of lack of a transaction record and documentation owing to the difficulty of making follow-ups on mobile payments while some participants were sceptical about the possible errors in payment transactions.

Compromising privacy was also perceived as a risk by some participants in Mallat's (2007) study, who were reluctant to disclose their information to mobile payment service providers. Based on the above, perceived risk was included as an additional dimension in studying factors that have the propensity to inhibit the adoption of mobile payment services. Therefore, it can be hypothesised that:

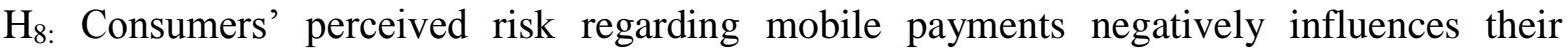
adoption of mobile payment services.

\section{The moderating effects of gender}

There seems to be a general consensus among researchers that demographic differences should be taken into account, when planning mobile marketing strategies (Mukherjee, 2012; Karjaluoto, Leppaniemi, Standing, Kajalo, Merisavo, Virtanen \& Salmenkivi, 2006), including mobile payment services. Despite growing research efforts to determine the effect of gender on the adoption of new and self-service technologies, there have been conflicting 
results. Some studies suggest that men are more predisposed to accepting technological innovations than women are (Ferreira, da Rocha \& da Silva, 2014) while other studies have found no significant influence in mobile technology (Jaradat \& Al Rababaa, 2013; Kabata, 2015). To the best knowledge of the authors, there are no empirical studies to report the moderating effects of gender on the various factors that influence the adoption of mobile payment services in South Africa, where mobile payment services are experiencing rapid growth.

Understanding the effect of gender differences is important in market segmentation as is also the understanding of buyer behaviour and the development of potential new product opportunities (Kimloglu, Nasir \& Nasir, 2010). Thus, this study concurs with many scholars that have proposed that there is a need for more rigorous studies that could yield a deeper understanding of consumer behaviour in general as well as any differences in user characteristics (Karjaluoto et al., 2006).

\section{Methodology}

\section{Sampling and data collection}

The target population for this study consisted of adult (18+) South African mobile phone users who have downloaded a mobile payment application. The data were collected by using an online self-completion questionnaire administered in all nine provinces in South Africa. Participant recruitment for the study was done through a market research firm using convenience sampling from their consumer panel. The participants were incentivised by the market research firm's standard practices. The questionnaire was hosted on the market research firm's online server.

Prior to completing a survey, ethical procedures require researchers to ask the potential participants to give informed consent indicating that they voluntarily wish to participate in 
the survey. Upon registration, consumer panel members give their consent to participate in the surveys. The potential panel member goes through a double opt-in process which means that the respondent agrees twice that they are prepared to answer surveys and they also have the option to withdraw from the panel before being added to the database.

\section{Sample profile}

Table 1 represents the demographic profile of the participants. A sample of 416 was realised; and it comprised almost an equal split between males and females.

Table 1. Sample and population characteristics

\begin{tabular}{|l|l|l|}
\hline Sample characteristic & Frequency & Percent (\%) \\
\hline Gender & & \\
\hline Male & 213 & 51.2 \\
\hline Female & 203 & 48.8 \\
\hline Age & & \\
\hline $18-21$ & 74 & 17.8 \\
\hline $22-29$ & 149 & 35.8 \\
\hline $30-39$ & 126 & 30.3 \\
\hline $40-49$ & 44 & 10.6 \\
\hline $50+$ & 23 & 5.5 \\
\hline Level of education & & \\
\hline High school & 68 & 16.3 \\
\hline Degree/Certificate/Diploma & 258 & 62 \\
\hline Postgraduate qualification & 90 & 21.6 \\
\hline Monthly income & & \\
\hline$<$ R 15 000 & 139 & 33.4 \\
\hline R16 000 - R25 999 & 88 & 21.2 \\
\hline R26 000 - R35 999 & 58 & 13.9 \\
\hline R36 000 - 45 999 & 31 & 7.5 \\
\hline R46 000 - R55 999 & 19 & 4.6 \\
\hline R56 000+ & 23 & 5.5 \\
\hline Prefer not to answer & 58 & 13.9 \\
\hline & & \\
\hline
\end{tabular}

The majority of respondents were aged between 22 and 29 years, which is similar to the South African youth population of 36.2\% (Statistics SA, 2016). Of the 416 participants, $62 \%$ have either a college degree, certificate or diploma qualification while approximately $33 \%$ earned a monthly income before interest and tax of less than R15 000 (approximately $\$ 1100$ ). 
Respondents mainly used their apps to buy restaurant meals, followed by take-away meals, groceries, purchasing of electronic products, paying bills, as well as purchasing food and beverages in food markets.

The most used mobile payment application was the SnapScan (44\%), followed by Zapper with $22.8 \%$. Approximately $34 \%$ of the respondents indicated that they use their payment app every month while $25 \%$ use the app weekly, followed by $7 \%$ of the participants who indicated that they use their payment app daily.

\section{Instrument design and measurements}

The previously validated measures used in this study were sourced from the literature and they were adapted to reflect the context of the study. The self-administered online questionnaire comprised six sections. Section A provided the introduction to the study, screening questions, and questions relating to respondents' knowledge about the various mobile payment apps that are currently available in South Africa. This section also asked the respondents to identify the products and the mobile payment apps that they had used before. Section B contained statements measuring consumers' readiness to adopt mobile payment services. The constructs included optimism, innovativeness, convenience, compatibility, discomfort, insecurity, perceived cost, perceived risk and the adoption of mobile payment services. A 7-point Likert type response format was used and the scale points ranged from 1 (strongly disagree) to 7 (strongly agree). Section C measured the demographic profile of the respondents with respect to age, gender, educational level, occupation and household income.

The questionnaire was pre-tested among 30 respondents from the study population in order to assess the reliability of the measurement scales. Based on the feedback received, minor changes were made to the wording of some scales in order to better reflect the context of the study, after which the questionnaire was fielded. 


\section{Data analysis and results}

\section{First and second order factors}

The original TRI has four factors: optimism and innovativeness as drivers; and discomfort and insecurity, as potential inhibitors. The two additional potential drivers: convenience and compatibility, and the two additional potential inhibitors from the literature, namely perceived risk and cost were included in the TRI model, in order to measure the adoption of mobile payment services. Confirmatory factor analysis (CFA) was done on all the drivers and inhibitors. Bearing in mind that the constructs were categorised into drivers and inhibitors, it was investigated to see whether second-order factor models exist that could be more appropriate than the first-order factor model. The purpose of the test was to see whether latent constructs could be derived that represent the four drivers and the four inhibitors.

Ideally, the target coefficient value should fall between 0.9 and 1 (Hair, Black, Babin, Anderson \& Tatham, 2006). The target coefficients that were calculated for both the secondorder factor models, were 0.82 and 0.80 respectively, indicating no adequate statistical reasoning to use the second-order factor models. Therefore, the first-order presentation was maintained.

\section{Scale reliability and validity}

\section{Convergent validity}

Confirmatory factor analysis (CFA) was performed to assess the convergent and discriminant validity of the scales. Table 2 contains the results of the CFA and Cronbach's Alpha values. Convergent validity was evaluated based on the significance of the factor loadings as suggested by Fornell and Larker (1981). Items C1 for optimism and C16 for insecurity constructs were eliminated from further analysis because the factor loadings were below the rule-of-thumb specifying values equal to or greater than 0.5, as acceptable (Hair et al., 2006). 
Table 2. Results of the measurement model

\begin{tabular}{|c|c|c|c|c|c|}
\hline Construct & Items & $\begin{array}{l}\text { Factor } \\
\text { loadings }\end{array}$ & $\begin{array}{l}\text { Cronbach's } \\
\text { Alpha }\end{array}$ & CR & AVE \\
\hline \multirow[t]{4}{*}{ Innovativeness } & Innov. C6 & 0.72 & 0.76 & 0.76 & 0.50 \\
\hline & Innov. C5 & 0.63 & & & \\
\hline & Innov. C7 & 0.60 & & & \\
\hline & Innov. C8 & 0.76 & & & \\
\hline \multirow[t]{4}{*}{ Convenience } & Conven. C24 & 0.70 & 0.84 & 0.79 & 0.50 \\
\hline & Conven. C22 & 0.76 & & & \\
\hline & Conven. C21 & 0.74 & & & \\
\hline & Conven. C23 & 0.62 & & & \\
\hline \multirow[t]{3}{*}{ Compatibility } & Compat. C27 & 0.74 & 0.84 & 0.83 & 0.62 \\
\hline & Compat. C26 & 0.78 & & & \\
\hline & Compat. C25 & 0.85 & & & \\
\hline \multirow[t]{3}{*}{ Optimism } & Optim. C4 & 0.58 & 0.77 & 0.75 & 0.52 \\
\hline & Optim. C2 & 0.77 & & & \\
\hline & Optim. C3 & 0.79 & & & \\
\hline \multirow[t]{4}{*}{ Discomfort } & Discom. C12 & 0.65 & 0.75 & 0.76 & 0.50 \\
\hline & Discom. C11 & 0.68 & & & \\
\hline & Discom. C10 & 0.75 & & & \\
\hline & Discom. C9 & 0.58 & & & \\
\hline \multirow[t]{3}{*}{ Insecurity } & Insec. C15 & 0.72 & 0.76 & 0.78 & 0.52 \\
\hline & Insec. C14 & 0.79 & & & \\
\hline & Insec. C13 & 0.64 & & & \\
\hline \multirow[t]{3}{*}{ Cost } & Cost C30 & 0.85 & 0.87 & 0.85 & 0.65 \\
\hline & Cost C29 & 0.88 & & & \\
\hline & Cost C28 & 0.67 & & & \\
\hline \multirow[t]{3}{*}{ Risk } & Risk C33 & 0.84 & 0.77 & 0.87 & 0.69 \\
\hline & Risk C32 & 0.89 & & & \\
\hline & Risk C31 & 0.76 & & & \\
\hline
\end{tabular}

All the other items were retained as they exceeded the cut-off point of 0.5 , resulting in constructs demonstrating convergent validity. The composite reliability index and the Cronbach's alpha coefficients (internal consistency) exceeded the cut-off point of 0.7 level for each construct, as suggested by Zikmund, Babin, Carr and Griffin (2010), thereby indicating good reliabilities of the scales. However, in the case of the discomfort construct, the average variance extracted (AVE) is 0.48 ; and we acknowledge that this is slightly below the stated cut-off point of 0.5 (Zikmund et al., 2010). However, according to Nunnally 
(1978) a Cronbach's Alpha above 0.7 implies convergent validity and as all the factor loadings for discomfort were also above 0.5 , hence, the construct was retained.

\section{Discriminant validity}

The discriminant validity of the scales was assessed by considering the square roots of the AVE scores and the cross loading criterion as recommended by Fornell and Larcker (1981). According to these authors, the square root of the AVE should be greater than all the correlations between each pair of constructs. From Table 3, it is evident that the AVE for all factors was greater than the corresponding cross loadings to demonstrate adequate discriminant validity with the exception of convenience. The square root of the AVE for convenience $(0.71)$ is not higher than the correlation between compatibility and convenience (0.72). Therefore, it was decided to use a Chi-squared difference test between the unconstrained and the constrained model as suggested by Shiu, Pervan, Bove and Beatty (2009), in order to confirm whether convenience and compatibility are two separate constructs.

A chi-square difference value of greater than 3.84, with 1 degree of freedom (Shiu et al., 2009) allows for the rejection of the null hypothesis at the 5\% significance level. The difference in the calculated Chi-square values between compatibility and convenience was $51.265(d f=1)(113.717-62,452=51.265>3.84)$, which is greater than the cut-off point of 0.384 (Shiu et al., 2009). The difference in the Chi-square values and the bias-corrected confidence interval for the correlation $($ BBCI Lower $=0.769$, BBCI Upper $=0.912$ ) was therefore confirming discriminant validity, and this indicates that convenience and compatibility are indeed two unique constructs. 
Table 3. Discriminant validity of the factors

\begin{tabular}{|l|l|l|l|l|l|l|l|l|}
\hline & Innov. & Conven. & Compat. & Optim. & Discom. & Insec. & Cost & Risk \\
\hline Innov. & $\mathbf{0 . 7 0 0}$ & & & & & & & \\
\hline Conven. & 0.193 & $\mathbf{0 . 7 1 0}$ & & & & & & \\
\hline Compat. & 0.263 & 0.723 & $\mathbf{0 . 7 9 0}$ & & & & & \\
\hline Optim, & 0.177 & 0.445 & 0.339 & $\mathbf{0 . 7 2 0}$ & & & & \\
\hline Discom, & 0.007 & 0.000 & 0.001 & 0.004 & $\mathbf{0 . 6 9 0}$ & & & \\
\hline Insec, & 0.014 & 0.013 & 0.026 & 0.092 & 0.184 & $\mathbf{0 . 7 2 0}$ & & \\
\hline Cost & 0.107 & 0.118 & 0.157 & 0.059 & 0.037 & 0.013 & $\mathbf{0 . 8 1 0}$ & \\
\hline Risk & 0.114 & 0.153 & 0.171 & 0.183 & 0.000 & 0.022 & 0.154 & $\mathbf{0 . 8 3 0}$ \\
\hline
\end{tabular}

Note: The square root of the AVE (Average Variance Extracted) is shown on the diagonal of the matric in bold

To measure the goodness-of-fit of the model, estimates for the degrees of freedom (X2 /df), incremental fit index (IFI), Tucker-Lewis index (TLI) and root mean square error of approximation (RMSEA) were measured as recommended by Hair et al. (2006). It is recommended that the X2/df should be less than 3 and the values for CFI and IFI should be greater than 0.9 while an RMSEA value below 0.08 indicates a good fit (Hooper, Coughlan \& Mullen, 2008). Thus, the results of the measurement model correspond to a good fit (Hooper et al., 2008). Table 4 reports the model fit indices of the CFA results. The fit indices were $\chi 2 /$ Degree of freedom $=2.291 ;$ comparative fit index $($ CFI $)=0.908 ;$ IFI $=0.909 ;$ RMSEA $=$ 0.056 .

Table 4: CFA fit statistics

\begin{tabular}{|l|l|}
\hline Fit indices & Overall model \\
\hline Chi square & 801.811 \\
\hline$P$ & 0.000 \\
\hline$D f$ & 350 \\
\hline$X^{2} / d f$ & 2.291 \\
\hline CFI & 0.908 \\
\hline IFI & 0.909 \\
\hline RMSEA & 0.056 \\
\hline
\end{tabular}

From Table 4, it is evident that there is an adequate model fit. 


\section{Multiple-regression analysis and hypotheses testing}

Multiple-regression analysis (MRA) was used to determine the influence of the identified drivers and inhibitors in consumers' adoption of mobile payment services. As in many other studies, the researchers checked for outliers, data normality, linearity, homoscedasticity and the independence of the residuals. Normality tests were conducted by visual inspection of the Probability-Plot (P-P) of the Regression Standardised Residual and the scatter plot (Pallant, 2016) while multicollinearity was assessed by considering the variance inflation factors (VIF) and the tolerance values. None of the assumptions for normality, linearity, homoscedasticity and the independence of residuals were violated. The regression model explains $53 \%$ and an adjusted $\mathrm{R}^{2}$ of $52 \%$ of the variance in consumers' adoption of mobile payment services.

The results of the model in Table 5 indicate that the factors 'perceived cost', 'perceived risk' and 'insecurity' are significant inhibitors while 'convenience' and 'compatibility' are significant drivers in the adoption of mobile-payment services. However, convenience makes the strongest unique contribution $($ Beta $=0.249)$, followed by perceived cost $($ Beta $=0.247)$, compatibility $($ Beta $=0.205)$, perceived risk $($ Beta $=0.160)$, and insecurity which makes a negative unique contribution of (Beta $=-1.05)$.

Table 5. Drivers and inhibitors of mobile-payment adoption

\begin{tabular}{|c|c|c|c|}
\hline \multirow[t]{2}{*}{ Model } & $\begin{array}{l}\text { Standardized } \\
\text { Coefficients }\end{array}$ & \multirow[t]{2}{*}{$\mathbf{t}$} & \multirow[t]{2}{*}{ p-value } \\
\hline & Beta & & \\
\hline (Constant: drivers) & & 4.679 & 0.000 \\
\hline Total optimism & 0.058 & 1.359 & 0.175 \\
\hline Total innovativeness & 0.063 & 1.625 & 0.105 \\
\hline Total convenience & 0.248 & 5.047 & $0.000 *$ \\
\hline Total compatibility & 0.210 & 4.244 & $0.000 *$ \\
\hline \multicolumn{4}{|l|}{ (Constant: inhibitors) } \\
\hline Total insecurity & -0.096 & -2.619 & 0.009* \\
\hline Total discomfort & -0.006 & -0.159 & 0.874 \\
\hline Total cost & 0.248 & 6.469 & $0.000 *$ \\
\hline Total risk & 0.164 & 4.205 & 0.000* \\
\hline
\end{tabular}


The results show that optimism and innovativeness are not significant in influencing consumers to adopt mobile payment services; while discomfort is not a significant inhibitor.

To test the statistical significance of the results, an ANOVA test was conducted (Pallant, 2016). The p-value of 0.000 indicates that the model is statistically significant for the overall data. The results of the hypotheses testing are shown in Table 6.

Table 6. The results of the hypotheses tested in this study

\begin{tabular}{|c|c|}
\hline Alternative hypotheses & Result \\
\hline $\begin{array}{l}\mathrm{H}_{1} \text { : Consumers' optimism regarding mobile payments positively influences the } \\
\text { adoption of mobile-payment services. }\end{array}$ & $\mathrm{H}_{1}$ Not supported \\
\hline $\begin{array}{l}\mathrm{H}_{2} \text { : Consumer innovativeness regarding mobile payments positively influences } \\
\text { the adoption of mobile-payment services. }\end{array}$ & $\mathrm{H}_{2}$ Not supported \\
\hline $\begin{array}{l}\mathrm{H}_{3}: \text { Consumers' perceptions of convenience regarding mobile payments } \\
\text { positively influences the adoption of mobile-payment services. }\end{array}$ & $\mathrm{H}_{3}$ Supported \\
\hline $\begin{array}{l}\mathrm{H}_{4} \text { : Consumers' perceptions of compatibility regarding mobile payments } \\
\text { positively influence the adoption of mobile-payment services. }\end{array}$ & $\mathrm{H}_{4}$ Supported \\
\hline $\begin{array}{l}\mathrm{H}_{5} \text { : Consumers' perceptions of insecurity regarding mobile payments negatively } \\
\text { influence their adoption of mobile-payment services. }\end{array}$ & $\mathrm{H}_{5}$ Supported \\
\hline $\begin{array}{l}\mathrm{H}_{6} \text { : Consumers' perceptions of discomfort regarding mobile payments negatively } \\
\text { influence their adoption of mobile-payment services. }\end{array}$ & $\mathrm{H}_{6}$ Not supported \\
\hline $\begin{array}{l}\mathrm{H}_{7} \text { : Consumers' perceived cost regarding mobile payments negatively influences } \\
\text { their adoption of mobile-payment services. }\end{array}$ & $\mathrm{H}_{7}$ Supported \\
\hline $\begin{array}{l}\mathrm{H}_{8} \text { : Consumers' perceived risk regarding mobile payments negatively influences } \\
\text { their adoption of mobile-payment services. }\end{array}$ & $\mathrm{H}_{8}$ Supported \\
\hline
\end{tabular}

\section{Moderating effects of gender}

To investigate whether gender moderates the relationship between the factors (drivers and inhibitors) and the adoption of mobile payment services, hierarchical regression was used. Firstly, the effects of each predictor and the moderator variables were interpreted. As indicated in Table 7, Model 1 explained 53.1\% of variance in which insecurity, convenience, compatibility, cost and the perceived risk constructs were significant predictors. Secondly, the significance of the moderator effect was tested and the resulting Model 2 explained $54.9 \%$ of the variance as a result of the interaction of gender as a moderator on the drivers and inhibitors of mobile payment services.

The $R^{2}$ value improved from Model $1(0.531)$ to Model $2(0.549)$ while the significant $\mathrm{F}$ change confirms the moderating effect. 
Table 7: The effects of predictor and moderator variables

\begin{tabular}{|c|c|c|c|}
\hline Model & $\begin{array}{l}\text { R } \\
\text { Squared }\end{array}$ & $\begin{array}{l}\text { F } \\
\text { Change }\end{array}$ & Sig. F Change \\
\hline $1^{\mathrm{a}}$ & 0.531 & 51.166 & .000 \\
\hline $2^{b}$ & 0.549 & 2.216 & .032 \\
\hline \multicolumn{4}{|c|}{$\begin{array}{l}\text { a. Predictors: (Constant), Total risk, Total discomfort, Gender, Total Convenience, Total insecurity, Total cost, Total } \\
\text { Innovativeness, Total optimism, Total compatibility }\end{array}$} \\
\hline \multicolumn{4}{|c|}{$\begin{array}{l}\text { b. Predictors: (Constant), Total risk, Total discomfort, Gender, Total Convenience, Total insecurity, Total cost, Total } \\
\text { Innovativeness, Total optimism, Total compatibility, Int. Disc._G, Int. Cost_G, Int. Insec._G, Int. Risk_G, Int. } \\
\text { Conven._G, Int. Innov._G, Int. Compat._G, Int. Opt._G. }\end{array}$} \\
\hline
\end{tabular}

The results indicated in Table 8 of Model 2 show that gender moderates only the effects of convenience on the adoption of mobile-payment services. There are no interaction effects of gender on the other seven factors tested in this study. On closer inspection, it emerged that males $(M=6.038)$ put more emphasis on the convenience derived from the use of mobile payments than do their female counterparts $(M=5.906)$.

Table 8: The significance of the moderating effect

\begin{tabular}{|c|c|c|c|}
\hline Model & Beta In & $\mathbf{T}$ & Sig. \\
\hline \multicolumn{4}{|l|}{ Model $1^{\mathrm{a}}$} \\
\hline Optm._G & 0.063 & 1.462 & 0.145 \\
\hline Innov._G & 0.047 & 1.195 & 0.233 \\
\hline Disc._G & 0.005 & .146 & 0.884 \\
\hline Insec._G & -0.100 & -2.602 & 0.010 \\
\hline Conven._G & 0.249 & 5.067 & 0.000 \\
\hline Compat._G & 0.208 & 4.194 & 0.000 \\
\hline Cost_G & 0.245 & 6.385 & 0.000 \\
\hline Risk_G & 0.161 & 4.106 & 0.000 \\
\hline \multicolumn{4}{|l|}{ Model $2^{b}$} \\
\hline Optm._G & 0.045 & 1.039 & 0.300 \\
\hline Innov._G & 0.208 & 1.458 & 0.146 \\
\hline Disc._G & -0.064 & -.564 & 0.573 \\
\hline Insec._G & -0.172 & -1.460 & 0.145 \\
\hline Conven._G & -0.203 & -1.339 & 0.181 \\
\hline Compat._G & 0.363 & 2.328 & 0.020 \\
\hline Cost_G & 0.095 & .8140 & 0.416 \\
\hline Risk_G & 0.171 & 1.438 & 0.151 \\
\hline Int. Optm._G & 0.950 & 0.631 & 0.528 \\
\hline
\end{tabular}




\begin{tabular}{|c|c|c|c|}
\hline Int. Innov._G & -0.025 & -0.20 & 0.842 \\
\hline Int. Disc._G & 0.089 & 0.858 & 0.391 \\
\hline Int. Insec._G & 0.096 & 0.890 & 0.374 \\
\hline Int. Conven._G & 0.354 & 3.100 & 0.002 \\
\hline Int. Compat._G & 0.123 & 1.087 & 0.278 \\
\hline Int. Cost_G & 0.177 & 1.659 & 0.098 \\
\hline Int. Risk_G & 0.089 & 0.813 & 0.417 \\
\hline \multicolumn{4}{|c|}{$\begin{array}{l}\text { a. Dependent Variable: Total adoption } \\
\text { Predictors in the Model: (Constant), Total risk, Total discomfort, Gender, } \\
\text { Total Convenience, Total insecurity, Total cost, Total Innovativeness, Total } \\
\text { optimism, Total compatibility }\end{array}$} \\
\hline \multicolumn{4}{|c|}{$\begin{array}{l}\text { b. Dependent Variable: Total adoption } \\
\text { Predictors: (Constant), Total risk, Total discomfort, Gender, Total } \\
\text { Convenience, Total insecurity, Total cost, Total Innovativeness, Total } \\
\text { optimism, Total compatibility, Int. Disc._G, Int. Cost_G, Int. Insec_G, Int. } \\
\text { Risk_G, Int. Conven._G, Int. Innov._G, Int. Compat._G, Int. and Optm._G }\end{array}$} \\
\hline
\end{tabular}

\section{Discussion and implications}

This empirical study analysed consumers' readiness to embrace mobile payment services. To further the understanding of consumers' adoption behaviour, the technology-readiness index (TRI) was used to ground the study in which the factors were categorised into drivers and inhibitors and the moderating effect of gender was investigated. Contrary to the existing literature (Yang et al., 2012; Parasuraman \& Colby, 2014) consumers' levels of optimism and innovativeness were found to be insignificant drivers while discomfort emerged as an insignificant inhibitor of consumers' readiness to adopt mobile payment services. These results cast a shadow on the robustness of the TRI applied in new mobile technology in an emerging market context but they show support for what several other researchers alluded to that there might be additional and apparently even better factors that could drive or inhibit the adoption of mobile payment services.

However, the results have significant managerial implications. To enhance the adoption of mobile payment services, service providers should focus on promoting the benefits of mobile payment services that consumers view as important rather than promoting only the features of the application. The primary features that garner more attention in advertisements of mobile 
payments include the design features, specifications and form, rather than the underlying benefits to the end consumers. For example, a reduction in cash handling may reduce losses that may arise from theft and fraud such that promoting a cashless society may enhance consumers' optimism levels towards new mobile payment services but also reduce safety concerns as a result of carrying cash, especially for women.

The results also indicate that consumers' perceived convenience and compatibility are significant drivers while insecurity, perceived cost and perceived risk significantly inhibit the adoption of mobile payment services. These findings are particularly important because these significant drivers and inhibitors are not part of the original TRI except for insecurity. Although the results are consistent with those of previous studies (Herzberg, 2003; Obe \& Balogun, 2007), it is important to discuss the implications of these drivers and inhibitors to enhance managerial decision-making.

One way to provide convenience as a benefit is to develop mobile payment apps that are compatible with one another within the mobile payment space. For instance, South Africa's commonly used apps, FlickPay, SnapScan and Zapper are available for both iOS and Android devices which creates a platform for interlinking different applications across technological functionalities (Barnajee \& Wigginton, 2016). However, these payment apps can only be linked to users' credit, Visa or Master Cards, thus excluding certain groups of people. Service providers should endeavour to develop mobile payment apps that can be linked to debit cards, which are more prevalent in South Africa and would ensure more inclusivity and enable more people to access mobile payment apps.

Mobile payment service providers must also invest in payment applications that are compatible not only with mobile payments, but also with users' lifestyle. The challenge facing service providers is to develop and communicate mobile payment services that inspire 
consumers in a way that attracts even the less interested consumers to start regarding mobile payments as suited to their purchase behaviours. Consumers will seek out those new innovations which offer the best value for money and those about which they are educated (Pham \& Ho, 2015). Hence, for the adoption of mobile payment services, it is necessary that service providers make consumers aware of the availability of mobile payment applications; and explain how they add value.

Given the moderating effect of gender, companies should initiate advertising campaigns targeting women opinion leaders in advertisements, which can in turn encourage and educate other women to enjoy the convenience of mobile payments. This can be done successfully through social networks, blogs, and websites, in order to capitalise on social influence. Service providers should also develop creative targeted promotions including incentives for women to adopt mobile payments and unlock this substantial market opportunity. Such promotions can include women portrayed in television and radio advertisements and billboards to create a sense of financial inclusion, empowerment and independence, thus, transforming their lives.

The diversity and fragmentation of mobile payments requires consumers to store their credentials on a variety of mobile payment platforms which makes consumers more susceptible to hackers and other fraudsters. Unless and until service providers manage to collaborate, consumers will continue to feel insecure to enter their personal information multiple times into mobile payment apps owned by different service providers.

The banks are important players in the mobile payment services since mobile payments are linked to users' bank cards. Available reports indicate that banks are experiencing potential risks of information security breaches which now cost the global corporate sector in excess of $\$ 388$ billion annually (Jacob \& Antony, 2016). Security violations in banks emanate from 
both within (employees entrusted with safeguarding consumers' financial assets) and outside (threats of hackers, spyware and virus attacks) and this has led to the low adoption of mobile payment services. It is therefore important for service providers to work together and re-think information security in order to mitigate the threats of both inside and external attacks on mobile payments.

The results suggest that the costing of mobile payment transactions should be transparent and free from any hidden costs that may inhibit the adoption of the payment app. Mobile payment apps such as SnapScan, Zapper and FlickPay are purportedly free to download increasing accessibility for all. The notion that downloads are free is tantamount to insincerity on the part of service providers because the users require internet connection for any download and this costs consumers in data charges. To increase adoption, mobile payment service providers should not pass the transaction costs on to the consumers, rather, they should focus on increasing the benefits while keeping the transaction costs to a minimum.

\section{Limitations and future research}

As in any other study, this study has limitations but these limitations could provide direction for future research. Firstly, despite the fact that the empirical data were collected from all the nine provinces of South Africa, a limitation exists since the data were collected from one country only. Further studies are therefore required to test and validate the results of this study in other emerging countries.

Secondly, this study investigated only the moderating effect of gender on the adoption of mobile payment services. Other demographic factors such as age, household income, or education may require further investigation. Lastly, the results of the study indicate that optimism and innovativeness are not significant drivers while discomfort is an insignificant inhibitor to the adoption of mobile payments. These findings are surprising and incongruent 
with prior research. Ongoing research is needed to further explore the impact of these three factors on the adoption of mobile payment services.

\section{Conclusions}

Despite many attempts to understand mobile payment adoption, few studies have addressed the issue from an emerging country perspective and taking gender into consideration. This study does not only contribute to the applicability of the TRI to new contexts, but it also suggests various additional drivers and inhibitors that need to be considered in the adoption of mobile payment applications as well as offering various practical insights.

Overall, the success of mobile payments hinges on consumers trusting the new payment methods. Perhaps it is important to initially create a trustworthy brand for service providers before offering mobile payment services. Brand image is extremely important and it is vital that a positive image be maintained in the minds of the consumers. Furthermore, the significance of critical mass should not be underestimated. Suffice it to say that consumers' intention to adopt mobile payment services is influenced by the number of participating merchants, which in turn determines the opportunities available to consumers to use the mobile payment services. It may also be prudent for service providers to focus on promoting mobile payments in areas characterised by a large consumer base such as the retail and public transportation (Mallat, 2007) before venturing into other application areas.

Mobile-payment apps in emerging countries, such as South Africa may still be in their infancy but with adequate investment in infrastructure and effective promotion, they could become mainstream and they could significantly change the way people pay and get paid. Thus, a cashless society for all, resulting in significant socio-economic benefits, is within reach. 


\section{REFERENCES}

Ajzen, I. (1991). The theory of planned behaviour. Organisational Behaviour and Human Decision Processes, 50(2), 179-211.

Barnajee, P. M. \& Wigginton, C. (2016). Mobile payment and mobile point of sale. Retrieved from http://dupress.deloitte.com/dup-us-en/industry/retail-distribution/mpayments-mobilepos-system-in-retail.html? id=us:2el:3dc:tmttrends:eng:abt:053016

Business Tech. (2014). Number of smartphones in South Africa. Retrieved from http://businesstech.co.za/news/mobile/59175/the-number-of-smartphone-users-in-sa/.

Chong, A. Y. L., Chan, F. T. S. \& Ooi, K. B. (2012). Predicting consumer decisions to adopt mobile commerce: Cross-country empirical examination between China and Malaysia. Decision Support Systems, 53, 34-43.

Dahlberg, T., Guo, J. \& Ondrus, J. (2015). A critical review of mobile-payment research. Electronic Commerce Research and Applications, 14(5), 265-284.

Davis F. D. (1989) Perceived usefulness, perceived ease-of-use, and user acceptance of information technology. MIS Quarterly 13(3), 319-340.

De Kerviler, G., Demoulin, N. T. M. \& Zidda, P. (2016). Adoption of in-store mobile payment: Are perceived risk and convenience the only drivers? Journal of Retailing and Consumer Services, 1-39.

Ferreira, J. B., da Rocha, A. \& da Silva, J. F. (2014). Impacts of technology readiness on emotions and cognition in Brazil. Journal of Business Research, 67(5), 865-873.

Fripp, C. (2014). South Africa's mobile penetration is $133 \%$. Retrieved from http://www.htxt.co.za/2014/10/23/south-africas-mobile-penetration-is-133/. 
Fornell, C. \& Larcker, D. F. (1981). Structural equation models with observable variables and measurement errors. Journal of Marketing Research, 18(1), 39-50.

GSMA. (2014). State of the Industry 2014 - Mobile Financial Services for the Unbanked. Retrieved from http://www.gsmamobileeconomy.com/.

Hair, F. H., Black, W. C., Babin, B. J., Anderson, R. E. \& Tatham, R. L. (2006). Multivariate data analysis, 6th edn. Pearson-Prentice Hall.

Hooper, D., Coughlan, J. \& Mullen, M. (2008) Structural-equation modelling: Guidelines for determining model fit. Electronic Journal of Business Research Methods, 6(1), 53-60.

ITU. (2016). Key ICT indicators for developed and developing countries and the world (totals and penetration rates). Retrieved from http://www.itu.int/en/ITUD/Statistics/Pages/stat/default.aspx.

Jacob, N. A. \& Antony, G. V. (2016). A critical review of information-security threats faced by Indian banks. International Journal of Advanced Research in Computer Science and Management Studies, 4(9), 7-13.

Jia, L., Hall, D. \& Sun, S. (2014). The effect of technology usage habits on consumers' intention to continue to use mobile payments. Twentieth Americans Conference on Information Systems, Savannah: 1-12.

Jaradat, M. I. R. M. \& Al Rababaa, M. S. (2013). Assessing key factors that have an influence on the acceptance of mobile commerce, based on modified UTAUT. International Journal of Business and Management, 8(23), 102-112.

Kabata, D. (2015). Determinants of mobile payment use by consumers in Kenya. International Journal of Computer Applications \& Information Technology, 8(1), 152159. 
Karjaluoto, H., Leppaniemi, M., Standing, C., Kajalo, S., Merisavo, M., Virtanen, V. \& Salmenkivi, S. (2006). Individual differences in the use of mobile services among Finnish consumers. International Journal of Mobile Marketing, 1(2), 4-10.

Kim, C., Mirusmonov, M. \& Lee, I. (2010). An empirical examination of factors influencing the intention to use mobile payment. Computers in Human Behaviour, 26, 310-322.

Kimloglu, H., Nasir, V. A. \& Nasir, S. (2010). Discovering behavioural segments in the mobile phone market. Journal of Consumer Marketing, 27(5), 401-413.

Kiwanuka, A. (2015). Acceptance process: The missing link between UTAUT and diffusion of innovation theory. American Journal of Information Systems, 3(2), 40-44.

Lee, Y. K., Park, J. H., Chung, N. \& Blakeney, A. (2012). A unified perspective on the factors influencing usage intention towards mobile-financial services. Journal of Business Research, 65, 1590-1599.

Liao, Z., Shi, X. \& Wong, W. K. (2012). Consumer perceptions of the smartcard in retailing: An empirical study. Journal of International Consumer Marketing, 24(4), 252-262.

Liebana-Cabanillas, F., de Luna, I. R. \& Montoro-Rios, F. J. (2015). User behaviour in QR mobile-payment system: the QR payment acceptance model. Technology Analysis \& Strategic Management, 27(9), 1031-1049.

Liebana-Cabanillas, F., Sanchez-Fernandez, J. \& Munov-Leiva, F. (2014). Antecedents of the adoption of the new mobile-payment systems: the moderating effect of age. Computers in Human Behaviour, 35, 464-478.

Lin, C. H., Shih, H. Y. \& Sher, P. J. (2007). Integrating technology readiness into technology acceptance: the TRAM model. Psychology \& Marketing, 24(7), 641-657. 
Liu, Y. (2015). Consumer protection in mobile payments in China: A critical analysis of Alipay’s service agreement. Computer Law \& Security Review, 1-10.

Lu, J., Yu, C. S., Liu, C. \& Yao, J. E. (2003). Technology acceptance model for wireless internet. Electronic Networking Applications and Policy, 13(3), 206-222.

Lu, Y., Yang, S., Chau, P. Y. K. \& Cao, Y. (2011). Dynamics between the trust-transfer process and intention to use mobile-payment services: A cross-environment perspective. Information \& Management, 48, 393-418.

Mallat, N. (2007). Exploring consumer adoption of mobile payments: a qualitative study. Journal of Strategic information Systems, 16, 413-432.

Mpinganjira, M., Dos Santos, M. A. O., Botha, E., Du Toit, D., Erasmus, A. C., Maree, T. \& Mugobo, V. V. (2013). Consumer Behaviour: A South African Psychology and Marketing Applications, Oxford University Press: Southern Africa.

Mukherjee, J. (2012). Exploring the demographic differences in the adoption of mobilemarketing in India. Management \& Change, 6(1\&2), 61-78.

Nunnally, J. C. (1978). Psychometric theory, 2nd edn. New York: McGraw-Hill.

Obe, O. O. \& Balogun, V. F. (2007). Practice, trends and challenges of mobile commerce in Nigeria. Information Technology Journal, 6(3), 448-456.

Pallant, J. (2016). SPSS Survival manual: A step-by-step guide to data analysis using the SPSS program, 4th edn. Crow's Nest, NSW: Allen \& Unwin.

Parasuraman, A. (2000). Technology readiness index (TRI): a multiple-item scale to measure readiness to embrace new technologies. Journal of Service Research, 2(4), 307-320. 
Parasuraman, A. \& Colby, C. L. (2014). An updated and streamlined technology readiness index: TR 2.0. Journal of Service Research, 18(1), 59-74.

Peter, P. J. (1981). Construct validity: A review of basic issues and marketing practices. Journal of Marketing Research, 18(2), 133-145.

Pham, T. T. T. \& Ho, J. C. (2015). The effects of product-related, personal-related factors and attractiveness of alternatives on consumer adoption of NFC-based mobile payments. Technology in Society, 1-16.

Qasim, H. \& Abu-Shanab, E. (2015). Drivers of mobile payment acceptance: the impact of network externalities. Information Systems Frontiers, 1-14.

Ramos-de-Luna, I., Montoro-Rios, F. \& Liebana-Cabanillas, F. (2015). Determinants of intention to use NFC technology as a payment system: an acceptance-model approach. Information Systems E-Business Management, 1-22.

Rogers, E. M. (1995). Diffusion of innovations, 4th edn. New York: Free Press.

Schierz, P. G., Schilke, O. \& Wirtz, B. W. (2010). Understanding consumer acceptance of mobile payment services: an empirical analysis. Electronic Commerce Research and Applications, 9, 209-216.

Slade, E. L., Williams, M. D. \& Dwivedi, Y. K. (2014). Devising a research model to examine the adoption of mobile payments: an extension of UTAUT2. The Marketing Review, 14(3), 311-336.

Statistics SA. (2016). The population of South Africa. Retrieved from http://cs2016.statssa.gov.za/

Straub, E. T. (2009). Understanding technology adoption: theory and future directions for informal learning. Review of Educational Research, 79(2), 625-649. 
Teo, A. C., Tan, G. W. H., Ooi, K.B., Hew, T. S. \& Yew, K. T. (2015). The effects of convenience and speed in m-payment. Industrial Management \& Data Systems, 115(2), 311-331.

Venkatesh, V. \& Davis, F. (2000). A theoretical extension of the technology-acceptance model: Four longitudinal field studies. Management Science, 46(2), 186-204.

Walczuch, R., Lemmink, J. \& Streukens, S. (2007). The effect of service employees' technology readiness on technology acceptance. Information \& Management, 44, 206-215.

World Wide Worx. (2014). The SnapScan effect: how mobile payments made QR codes relevant in South Africa. Retrieved from http://memeburn.com/2015/05/the-snapscaneffect-how-mobile-payments-made-qr-codes-relevant-in-south-africa.

Yang, S., Lu, Y., Gupta, S., Cao, Y. \& Zhang, R. (2012). Mobile payment services' adoption across time: an empirical study of the effects of behavioural beliefs, social influences, and personal traits. Computers in Human Behaviour, 28, 129-142.

Zhou, T. (2013). An empirical examination of continuance intention of mobile-payment services. Decision Support Systems, 54, 1085-1091.

Zikmund, W. G., Babin, B. J., Carr, J. C. \& Griffin, M. (2010). Business research methods, 8th edn. Mason, OH: South-Western, CENGAGE Learning. 